\title{
Ni Rouges, ni Blancs. Quelques observations sur les insurrections paysannes durant la Guerre civile en Russie-Ukraine (1918-1922)
}

\author{
Alexis BERELOWITCH \\ a.berelowitch@gmail.com
}

\section{Doi :10.5077/journals/connexe.2021.e597}

\section{Résumé}

Cet article présente une synthèse des nouvelles connaissances sur la place de la paysannerie durant la Guerre civile en Russie de 1918 à 1922, obtenues grâce aux ouvertures des archives dans les années 1990 et leurs publications partielles par l'historien Viktor Danilov et le sociologue Teodor Shanin. Sans forcément bouleverser complètement l'image que l'on pouvait avoir précédemment sur cet épisode crucial de l'histoire russe du XX siècle, elles la modifient ou la précisent sur bien des points.

Tout d'abord, les soulèvements contre le pouvoir soviétique, bien plus nombreux qu'on ne le croyait auparavant, ont joué un rôle souvent décisif dans le déroulement de la Guerre civile, et notamment dans la décision d'instaurer la NEP. Ni « Rouges » ni " Blancs », les paysans s'opposaient à la politique prédatrice des uns et des autres. Toutefois, ce que l'on trouve dans les archives, ce sont les récits des soulèvements dont beaucoup ont pour point de départ les réquisitions de blé par le pouvoir bolchevique, opérées par les détachements spéciaux, ou les enrôlements forcés dans l'Armée rouge. Ces révoltes sont d'envergures diverses. Loin d'être monarchistes, les slogans des insurgés nous montrent un rejet de l'ancien régime et une adhésion aux soviets accompagnés d'un refus violent des bolcheviks, assimilés à des voleurs et des profiteurs. Les archives révèlent enfin dans le détail, certes la violence des insurgés, mais surtout celle de la répression massive dont ils furent victimes.

Mots-clés : Guerre civile, révolution, révolte, paysans, déserteurs, répressions, bolcheviks

\begin{abstract}
The aim of this article is to summarise the new understanding of the role played by the peasantry during the Russian Civil War from 1918 to 1922, made possible by the opening of archives in the 1990s and their incomplete publication by the historian Viktor Danilov and the sociologist Teodor Shanin. Although it does not radically overhaul the perception that one might have had previously of this crucial episode in twentiethcentury Russian history, they do modify or clarify it on many points.

First of all, the uprisings against Soviet power, which were much more widespread than previously thought, often played a decisive role in the course of the Civil War and in particular in the decision to establish the NEP. Neither "Reds" nor "Whites", the peasants opposed the predatory policies of both.

However, what we do find in the archives are accounts of uprisings, many of which sparked off by the Bolshevik power's requisitioning of wheat by special detachments or forced conscription into the Red Army. These revolts were of varying scope. Far from being monarchist, the slogans of the insurgents indicate a repudiation of the old regime and an endorsement of the soviets, along with a violent rejection of the Bolsheviks, who were regarded as thieves and profiteers. The archives reveal in detail the violence of the insurgents, but above all the massive repression they suffered.
\end{abstract}

Keywords: Civil war, revolution, revolt, peasants, deserters, repressions, Bolsheviks. 


\section{Introduction}

L'importance des mouvements paysans dans le cadre de la Guerre civile n'a jamais été niée ${ }^{1}$, mais le plus souvent, elle a été minimisée et réduite au rôle somme toute marginal de « bandes » et de « bandits », de force d'appoint ballotée entre Rouges et Blancs.

Cette vision largement partagée, au-delà même de l'historiographie soviétique, a été mise à mal, et les soulèvements paysans ont trouvéla place centrale qui leur revient dans le processus révolutionnaire grâce aux publications d'archives qu'on doit, avant tout, à deux spécialistes de la paysannerie russe : le sociologue Teodor Šanin (19302020) et l'historien Viktor Petrovič Danilov (1925-2004). Ces publications, qui se sont échelonnées entre 1994 et 2016, s’inscrivaient dans le cadre d'un projet lancé par ces deux grands chercheurs : « la Révolution paysanne 1902-1922 » (Данилов и Шанин 1994, 5-6). Selon leur conception, il y a unité et continuité des mouvements paysans entre ces deux dates (1902 étant le début des soulèvements paysans, qui culminèrent avec la révolution de 1905 et 1922 marquant la fin de la Guerre civile). Les paysans mirent en avant toujours la même revendication : " la terre et la liberté » [zemlja i volja]. La terre, ils l'obtinrent (ou la prirent) à partir de février et d'octobre 1917. Quant à la liberté, qui était celle de s'auto-organiser et de disposer librement des fruits de son travail, ils l'obtinrent, pour l'essentiel, avec l'instauration de la Nouvelle politique économique (NEP). Victoire, comme on le sait, de courte durée puisqu'elle fut remise en cause dès 1927-1928 et disparut pour longtemps (sinon pour toujours) $)^{2}$.

Les archives publiées depuis 1994, celles que nous avons évoquées, mais aussi d'autres, comme celles, par exemple, sur les soulèvements paysans en Sibérie (Шишкин 2000, 2001) ou des monographies, comme celle de I. Narskij sur l'Oural (Нарский 2001), nous permettent désormais de mieux voir les points suivants, concernant les luttes paysannes au cours de la guerre civile :

- L'étendue de ces mouvements : au-delà de ceux qui étaient répertoriés, ou bien

1 Encore que la très officielle Histoire de la guerre civile en URSS (le premier de ses cinq volumes avait pour rédacteurs : M. Gorkij, V. Molotov, K. Vorošilov, S. Kirov, A. Ždanov et I. Staline) n’a trouvé de place pour aucun des mouvements paysans dans son cinquième volume, consacré aux années finales de la Guerre civile. Seul fait exception le mouvement de Makhno, mentionné rapidement comme un ramassis de bandits puis comme des koulaks et des anarchistes (Буденный 1960, 164, 205).

2 Pour une vision générale de l'historiographie des mouvements paysans pendant la Guerre civile, voir les articles de V. Kondrašin (Кондрашин 2013, 24-47 и 2018, 39-45) et de V. Teplicyn (Теплицын 2002, 579-596). Voir également le chapitre 1 dans l'ouvrage de synthèse de V. Kondrašin sur les paysans dans La Paysannerie russe pendant la guerre civile, le plus complet à cette heure (Конндрашин 2009, 8-58). Sur l'histoire du projet de V. Danilov et de T. Šanin, voir également l'intervention de T. Šanin à la conférence à la mémoire de V. Danilov en mars 2005 (Шанин 2006, 30-37). 
connus, comme l'antonovščina ${ }^{3}$, l'armée de Nestor Makhno, le soulèvement du Don avec Filipp Mironov, la "guerre des kaftans » [Čapannaja vojna], le " soulèvement des fourches » [Viločnoe vosstanie], etc., il y eut des centaines, voire des milliers d'autres soulèvements, compris comme des actions violentes contre les autorités ayant une durée allant d'une journée à de nombreux mois ;

- Les motivations des paysans en révolte ;

- Le déroulement des soulèvements ;

- La répression et l'écrasement des soulèvements ;

- La vision qu'en avaient les autorités bolchéviques.

Les archives que j'ai retenues constituent des rapports provenant des différentes institutions étatiques impliquées dans la lutte contre les paysans : l'Armée rouge, la police politique ${ }^{4}$, le Commissariat du peuple des affaires intérieures (NKVD), les soviets de différents niveaux, les détachements chargés des réquisitions de ravitaillement [prodotrjady], les troupes intérieures (VOXR, Troupes de défense de la République), etc. C'est donc un regard extérieur (et hostile) qui préside à ces rapports. Les mouvements de Makhno et celui de Mironov, qui ont laissé leurs propres archives, nous offrent quant à eux la possibilité de les voir de l'intérieur. Ils constituent pourtant une exception. Heureusement, les divers rapports officiels citent abondamment les slogans et les divers appels des insurgés.

Cette origine (les archives des vainqueurs) introduit des biais évidents sur lesquels je reviendrai, notamment la définition des mouvements armés : bandits, koulaks, vert-koulaks, vert-socialistes-révolutionnaires (SR), etc., l'explication des mouvements par les menées des Blancs, des officiers (de l'armée tsariste), des koulaks ou des SR, qui exploiteraient des difficultés alimentaires, ou encore par les « excès » des prodotrjady ou par l'arriération congénitale des paysans ne comprenant pas les vertus du socialisme.

Ainsi, un rapport du troisième groupe des ČON (Détachements à destination spéciale [Časti osobogo naznačenija]) du district de Bougoulminski (en russe: бугульминский уезд) sur le «soulèvement des fourches » daté du 11 avril 1920 (donc post factum) donne l'explication suivante :

[...] Leur état d'esprit contre-révolutionnaire [...] s'explique premièrement par la lassitude des paysans et, deuxièmement et principalement, par leur arriération [temnota, littéralement obscurité], grâce [sic] à laquelle ils ne sont pas en état de voir clairement les buts de la mise en œuvre des idées du socialisme, d'ailleurs, à

3 Terme dépréciatif que les autorités soviétiques donnèrent au soulèvement dans la région de Tambov sous le commandement d'Antonov.

4 VČK, parfois abrégé en ČK et écrit en français Tchéka, pour Vserossïskaja Črezvyčajnaja komissija (Commission extraordinaire panrusse), puis OGPU pour Ob"edinennoe gosudarstvennoe polititčeskoe upravlenie (Direction politique d'État unifiée).

CONNEXE 7| 2021 - La Guerre civile après 1917 : les échelles d'un conflit et sa représentation 
proprement parler, on n'a même pas tenté, en de nombreux endroits, de les leur expliquer et de les introduire... (Данилов и Шанин 2002, 495).

Malgré ce biais, on peut se faire une idée assez précise des programmes mis en avant par les paysans révoltés, soit, dans certains cas, parce que nous disposons des archives des mouvements importants, soit parce que les rapports les exposent de manière plus ou moins détaillée.

\section{Programmes politiques}

Les programmes politiques sont le plus souvent peu élaborés, parfois même réduits à quelques slogans (n'oublions pas que nombre de soulèvements sont de très courte durée). Ils reprennent constamment les deux revendications historiques des paysans : la terre (pour l'essentiel obtenue) et la liberté (de s'organiser, de disposer librement de sa production), mise à mal par la prodrazvërstka (les réquisitions, avant tout des céréales). D'où les slogans « À bas les réquisitions, à bas les détachements de réquisition ». Les soviets, que les paysans ont transformé selon leurs propres traditions en assemblées de la communauté villageoise, ne sont pas mis en cause, mais on les veut sans les communistes. Dans un appel, le 10 mars 1919, les dirigeants du soulèvement de Stavropol, disent :

Camarades, frères de l'Armée rouge, nous travailleurs en révolte, nourrisseurs de toute la population russe, paysans, nous nous adressons à vous pour dire que nous ne nous soulevons pas contre le pouvoir soviétique, mais contre la dictature de la violence des communistes [...] Nous déclarons que le pouvoir soviétique reste en place. Les soviets ne sont pas supprimés mais doivent y être élues des personnes connues par les habitants du lieu. Nous ne nous écarterons pas d'un pas de la Constitution de la RSFSR et nous nous appuyons sur elle (Данилов и Шанин 2002, 105) (voir Document 1 en annexe).

Les slogans font souvent une différence, qui peut surprendre le lecteur d'aujourd'hui, entre les bolcheviks et les communistes, ou entre Lénine et Trotski («Vive Lénine, à bas Trotski ») ${ }^{5}$. Les bolcheviks (Lénine) sont ceux qui ont donné la terre (il serait plus exact de dire qu'ils ont sanctionné post factum les partages des terres), alors que les communistes (Trotski, chef de l'Armée rouge) sont ceux qui pratiquent notamment les réquisitions ou les levées de recrues.

Ainsi, dans un dialogue partéléphone assezétonnantentreIosifVarejkis(secrétaire du parti de la région de Simbirsk) et Poručikov, un des leaders du soulèvement de la région, ce dernier dit au premier :

Il n’y a pas et il n’y a pas eu chez nous de soulèvements koulaks ; il n'y a pas de

5 Un des slogans d'un détachement de l'armée d'Antonov aurait été « Vive l’Armée rouge ! Frappe les communistes et à bas Trotski ! Vive Lénine et l'Assemblée constituante ! ». Information opérationnelle du département secret de la VČK du 25 octobre 1920 (Берелович и Данилов 1998, 347). 
contre-révolutionnaires. [Nous] sommes contre les réquisitions injustes de blé et de bétail. Nous saluons le parti des bolcheviks et n’allons pas contre eux, nous allons contre la violence exercée contre nous par les communistes.

Poručikov invite ensuite Varejkis à venir chez eux pour constater lui-même l'absence de koulaks et de contre-révolution (Данилов и Шанин 2002, 128).

Les revendications politiques démocratiques à l'instar de «Vive la Constituante » et/ou l'exigence d'élections au suffrage universel sont, elles aussi, souvent mises en avant même si de manière moins fréquente que les précédentes. Ainsi, dans le programme des insurgés de Tambov (l'antonovščina), on trouve sous le nom de l'Union de la paysannerie laborieuse [Sojuz trudovogo krest’janstva] les points suivants :

1. Égalité politique de tous les citoyens sans distinction de classes [...] ; 3. Réunion d'une Assemblée constituante élue au suffrage secret, universel et direct [...]; 6. Liberté de parole, de presse, de conscience, d'unions et de réunions (Данилов и Шанин 1994, 79-80).

Il nous faut rappeler ici - car l'historiographie soviétique officielle a profondément brouillé les cartes - que les leaders de grands soulèvements comme Aleksandr Antonov ou Aleksandr Sapožkov, sans parler de Mironov et de Makhno, n'étaient pas des « adversaires de la révolution » mais en étaient de farouches partisans. Ils le soulignent d'ailleurs dans les appels et autres documents parvenus jusqu'à nous. "Que les richards, les gardes-blancs et les popes », affirme Sapožkov, « ne se réjouissent pas : nous ne luttons pas pour eux, mais comme toujours pour la malheureuse paysannerie que les salauds [gady] qui se sont infiltrés dans le peuple, étouffent définitivement » (Данилов и Шанин 2002, 539).

À de rares exceptions près, on ne trouve pas de soulèvements monarchistes ${ }^{6}$, et toutes les définitions comme «la Vendée russe », la «Vendée de Sibérie » ou même, - malgré le poème de Marina Tsvetaeva -, la « Vendée du Don ${ }^{7}$ ne sont pas appropriées.

6 Quelques exemples : la VČK signale le 6 mars 1919 dans la province de Penza un soulèvement dirigé par des monarchistes, avec des drapeaux et des portraits de Nicolas II et d'Alexis (fils unique de Nicolas II et qui aurait été l'héritier du trône s'il n'avait pas déjà été fusillé en même temps que toute la famille de Nicolas II à cette date). Le président de la gubčeka (ČK au niveau de la province) de Penza signale un soulèvement " monarcho-religieux » dans un village du district de Krasnoslobodsk : « le soulèvement a explosé à cause de l'agitation clandestine de sectateurs et d'autres personnages douteux » (Берелович и Данилов 1998, 118, 310-311). Parmi les nombreux slogans que cite le Président de la gubčeka de Tioumen dans un rapport du 5 avril 1921 sur les soulèvements dans la région d'Ichim (Tioumen), par exemple «À bas les communistes, vive le pouvoir des soviets et le libre du commerce; Vive le gouvernement provisoire ; À bas les communistes. Vive le pouvoir paysan. Donnez du pain ", on trouve aussi le slogan " Dieu et Mikhaïl II (frère cadet de Nicolas II déjà fusillé à cette date) avec nous " (Шишкин 2000, 707-708).

7 Du moins si l'on pense à la figure centrale de Filipp Mironov. Voir le passionnant témoignage de I. Smilga sur le premier procès de Mironov en 1919 (Данилов и Шанин 1997, 484-485), mais, bien sûr, de nombreux cosaques, en particulier du Don, se joignirent aux armées blanches. 
Ajoutons que les SR, contrairement aux affirmations répétées des auteurs de rapports, ne jouaient pas, au vu des documents internes des insurgés, de rôle notable dans les soulèvements paysans. Les chefs de grands soulèvements, même quand ils étaient socialistes-révolutionnaires, comme Antonov ou Sapožkov, ne faisaient pas état de leur appartenance, même si Antonov avait, semble-t-il, mené des pourparlers avec le parti SR avant de créer son Union de la paysannerie laborieuse [Sojuz trudovogo krest’janstva (STK)] ${ }^{8}$. Ainsi, face aux accusations, notamment de la part de la Tchéka, selon lesquelles le parti SR était l'instigateur et l'organisateur du soulèvement de Tambov, le soi-disant responsable SR des soulèvements des régions de Tambov et de Voronej, Jurij Podbelskij, écrit, non sans ironie, du fond de la prison où il est détenu :

Il faut avoir une fantaisie débridée pour m'élever au rang de "plénipotentiaire de Comité central pour l'organisation des soulèvements de Tambov et Voronej » [...] Si un seul homme peut durant une année entière, à partir de Moscou, diriger simultanément des insurrections dans deux provinces éloignées de Moscou, il serait plus facile d'inventer une union fantastique d'Antonov avec les SR (même s'ils ont tous été arrêtés jusqu'au dernier et sont en prison (Данилов и Шанин 1994, 244-245).

\section{Comme l'écrit Igor' Narskij :}

La paysannerie ne courait pas, comme on l'affirme, des Rouges aux Blancs et des Blancs aux Rouges, comparant les deux pouvoirs et choisissant le plus acceptable pour eux. Elle s'était refermée sur elle-même, essayant de conserver l'autonomie que la révolution lui avait, par mégarde, offerte (Нарский 2001, 262).

De fait, en 1917 et jusqu'au début 1918, la campagne pouvait se sentir enfin libérée de la « ville » et penser qu'elle était devenue maîtresse de son destin. Elle résiste donc à l'intrusion violente du pouvoir bolchévique sous la forme de réquisitions de grains et chevaux, mobilisation, etc. C'est ce qu'exprime le Soviet révolutionnaire militaire [Revvoensovet] de la Première armée de la Justice [Pravda] dans un de ses appels en écrivant dans une syntaxe approximative, le 13 juillet 1920 :

[...] en réalité, nos conquêtes ont donné la liberté à nos ennemis, aux bourgeois, aux officiers [...] [on nous écrit] des décrets menaçants et [on nous] dicte nos conditions de vie : « Ne vis pas comme tu en as envie mais comme ils veulent » (Данилов и Шанин 2002, 520).

À ma connaissance, la première évocation d'un soulèvement paysan dans les rapports des services de renseignement, en l'occurrence celui publié dans le bulletin du narkomat (ministère) des affaires militaires, date du 4 juillet 1918. Il s'agit, y liton, d'un soulèvement dans la région militaire de Moscou :

Dans le district d'Odoev, sur la base des réquisitions des surplus de blé, eut lieu

8 Voir le rapport (anonyme) du représentant de Tambov à la conférence panrusse des socialistes révolutionnaires (8 septembre 1920) qui met à son actif la création de groupes du STK (Данилов и Шанин 1994, 63). 
une action importante de koulaks. Sept membres du soviet du district d'Odoev ont été battus et blessés, deux, selon des bruits persistants, ont été enterrés vivants. Les bandes organisées par les koulaks vont contre les soviets, elles sont armées de fusils de guerre, de grenades, de mitrailleuses, et, selon des bruits, de deux pièces d'artillerie légères. [...] On sent [la présence] d'une main expérimentée (Берелович и Данилов 1998, 71).

Dès ce premier document, on relève l'explication du soulèvement par les menées des koulaks et la présence d'un organisateur caché, les réquisitions étant le terrain sur lequel s'est développé le soulèvement, mais non sa cause véritable. De fait, beaucoup d'armes étaient en circulation sur le territoire de l'ancien Empire russe sortant de la guerre contre l'Allemagne. Les paysans insurgés pouvaient être armés des fusils rapportés par les démobilisés de la Première Guerre mondiale (puis par les déserteurs de l'Armée rouge passant dans le camp des insurgés), par la mainmise sur des armureries, entrepôts de matériel militaire, par les armes abandonnées par des troupes blanches en retraite, par les armes prises aux détachements de l'Armée rouge en cas de victoire lors d'affrontements, etc ${ }^{9}$. Compte tenu de l'extrême diversité des soulèvements (depuis le soulèvement spontané au cours d'une réquisition d'un village durant quelques heures jusqu'aux véritables armées de Makhno et de Mironov), les armements pouvaient aller des pieux et des fourches aux mitrailleuses et pièces d'artillerie. À l'exception de Makhno, qui disposait au moins d'un train blindé (voir Данилов и Шанин 2006), les insurgés paysans n'avaient pas d'armes lourdes, incompatibles avec l'extrême mobilité qui constituait l'un de leurs atouts principaux (avec celui de bénéficier, jusqu'à un certain stade du moins, du soutien de la population tant qu'ils agissaient sur leur territoire).

Il est difficile sinon impossible de donner le nombre total des soulèvements paysans. Une des raisons en est qu'il n'est parfois pas aisé de déterminer qui étaient précisément les insurgés. Si la situation est plus ou moins claire quand le rapport parle de koulaks (il s'agit de paysans, même si l'appellation de koulak est plus idéologique que sociologique), elle se complique quand il est question de bandits. Dans la majorité des cas, il s'agit, bien évidemment, de paysans, qualifiés par les autorités de bandits (j'y reviendrai), mais on ne peut exclure qu'il s'agisse parfois réellement de bandits. De même, les déserteurs sont le plus souvent des paysans, enrôlés de force dans l'Armée rouge, qui se sont joints à des soulèvements paysans ou en ont même été l'instrument moteur, mais il peut aussi s'agir, plus rarement toutefois, de bandes de déserteurs qu'on ne peut pas qualifier de paysans. Néanmoins, dans l'immense majorité des cas,

9 Comme par exemple, selon un rapport de la gubčeka de Tambov d'avril 1921, un détachement d'Antonov s'est emparé de quatre pièces d'artillerie, 500 obus, des fusils, des munitions en grande masse, du convoi de l'intendance, etc. (Данилов и Шанин 1994, 155).

CONNEXE 7| 2021 - La Guerre civile après 1917 : les échelles d'un conflit et sa représentation 
il s'agit bien de paysans, ce que nous confirme la définition que donne la Tchéka dans un rapport de synthèse du 11 décembre 1920, où elle donne la composition « socialede classe » des « bandes » :

[...] Les déserteurs (verts [zelenoarmejcy]) [...] par leur nature sociale sont des éléments aisés des campagnes, abrutis, désorientés, déclassés, ayant peur et des rouges et des blancs, cherchant à retrouver au plus vite leur vie tranquille de laboureur ; ils naviguent d'un camp à l'autre et tombent entre les griffes des gardesblancs, déclarés ou dissimulés, qui les organisent, les enrôlent dans des bandes, les rassemblent, etc. (Берелович и Данилов 1998, 364).

Enfin, un autre obstacle pour dénombrer les soulèvements tient au fait qu'une bonne part des rapports se contentent d'en signaler l'existence, sans plus de détails (et notamment le nombre des participants). À titre d'exemples, on peut prendre plusieurs rapports qui font le point à un moment donné :

- Le rapport du «département opérationnel de l'État-major des troupes de la VČK concernant l'implication de [ses] détachements dans l'écrasement des soulèvements contre-révolutionnaires du 1er octobre au 25 novembre 1918 » dénombre environ quarante soulèvements dans une partie de la Russie centrale (régions d'Orel, Oural, Petrograd, Iaroslavl, Moscou, Volga...), comme celui dans les environs d'Arsk :

[...] le soulèvement dans les environs d'Arsk a été réprimé, trente personnes fusillées, vingt blessées, arrêtées environ 310, confisquées environ 500 armes. [...] De notre côté ont péri au combat quatre soldats et un commissaire militaire (Берелович и Данилов 1998, 103-106) (voir document 2).

- Dans le rapport de la VČK datant de début août 1919 et portant sur toute la Russie, on arrive à un total de 32 soulèvements, dont le plus important compte 500 déserteurs « bien organisés » et armés de 200 fusils de guerre [vintovki] (Берелович и Данилов 1998, 156-166). Après avoir signalé le soutien dont les " bandes » bénéficient de la part de la population rurale et leur tendance à la concentration, un rapport de la Tchéka daté du 11 décembre 1920 énumère celles d'entre elles qui, outre la mahnovšćina, opèrent à la fin du mois de novembre en Ukraine, cinq sur la rive gauche [du Dniepr], quinze sur la rive droite, plus des satellites de Makhno et de plus petits groupes [šajki] (Берелович и Данилов 1998, 366-367).

- Dans un rapport, le Président du comité exécutif et le secrétaire du comité du RKP (Parti communiste russe) du district d'Atkarsk cherchent à faire le bilan des soulèvements dans la région de l'outre-Volga. Ils soulignent qu'en 1921, il ne reste plus que des «petites bandes » qu'ils divisent en «deux catégories ». Dans la première catégorie, on trouve des personnes dotées d'un psychisme d'aventuriers, des amateurs d'aventures et de l'argent facile. Dans la deuxième catégorie, on trouve des paysans trompés et lancés contre le pouvoir soviétique, 
enclins de voir dans ce dernier une des causes de la mauvaise récolte dont ils ont été frappés [un délicat euphémisme, nous sommes en 1921, l'année de la famine]. Les deux auteurs passent ensuite à une description des divers soulèvements et de leur répression. En annexe, le rapport contient une liste des « bandes » au premier de chaque mois avec le nombre d'insurgés. Le nombre de bandes importantes varie de quatre à vingt-deux, les plus petites étant regroupées en bandes inconnues et petites bandes. Le nombre d’insurgés varie lui de 720 personnes au $1^{\text {er }}$ décembre 1921, quand la répression (et la famine) ont mis fin aux soulèvements, à 10200 personnes au $1^{\text {er }}$ mars. L'importance des bandes varie, elle, de 6000 personnes (bande de Popov, district de Khvalynsk) à trente personnes (Katouchov, district de Kalmykov) (Данилов и Шанин 2002, 759$767)^{10}$.

Dans ce rapport comme dans tant d'autres, les paysans ne sont jamais des personnes conscientes ayant des raisons objectives de s'opposer au pouvoir soviétique. Ce sont soit des personnes au psychisme perturbé, soit des benêts trompés par des ennemis avérés du pouvoir soviétique (officiers, socialistes-révolutionnaires, etc.). Malgré cela, on peut constater quils sont motivés par des causes objectives et suffisamment précises.

\section{Motivations}

Les motivations de ces soulèvements sont presque toujours les mêmes. Il s'agit de réactions aux exactions des représentants de l'ordre (milices, prodotrjady, soldats de l'Armée rouge, VOXR, etc.) procédant aux réquisitions de grains, de chevaux (pour la remonte de l'Armée rouge), de bétail, mais aussi de beurre, œufs, etc., le tout s'accompagnant de violences sans limites : passages à tabac, femmes battues et violées, détention des paysans nus dans des granges non chauffées en hiver, pillages. Une autre cause fréquente est la résistance à l'enrôlement forcé dans l'Armée rouge, ceux qui y échappent venant grossir les rangs des déserteurs ${ }^{11}$. La mention des violences exercées contre les paysans, présente dans presque tous les rapports, montre que contrairement à la qualification d'« excès » que leur donnent les rapports,

10 Dans ses synthèses sur la paysannerie russe dans la guerre civile, basées sur des décennies de travail sur ce thème et une étude approfondie des archives, T. Osipova ne se risque pas à avancer un chiffre global (Осипова 1995 ; Осипова 2001). Cependant, elle avance des données partielles : au cours du premier semestre 1919, il y eut des soulèvements d'une certaine importance dans 124 districts de la Russie d'Europe (Осипова 1995, 123) ; dans la même période, 238 mouvements divers dans trois provinces (Orel, Voronej et Koursk) (Осипова 2001, 309) ; dans les quelques mois d'été 1918, il y aurait eu, dans la Russie centrale, 130 actions contre les soviets locaux, 154 actes de résistance contre les réquisitions et 75 soulèvements (Осипова 1995, 104). V. Kondrašin, lui, décompte trente soulèvements importants dans le bassin de la Volga en 1918-1921(Кондрашин 2009, 537-538).

11 T. Osipova reprend un décompte effectué par D. Kin à partir des rapports militaires (Д. Кин (1927), Деникинщина, Ленинград : Прибой, 44), selon lequel sur les 238 soulèvements du premier semestre 1919 dans les provinces de Voronej, Koursk et Orel, 72 étaient dus à des problèmes de ravitaillement, 51 à la mobilisation, 35 des soulèvements de déserteurs, 34 à des réquisitions, etc. (Осипова 1995, 128). 
il s'agit, bien au contraire, d’un comportement généralisé.

Les motifs religieux sont plus rares. Il s'agit généralement d'une résistance aux arrestations des ministres du culte et aux réquisitions des objets de culte. Le « soulèvement des fourches » (avec l'armée de l'Aigle noir, février-mars 1920) a réuni sur cette base chrétiens et musulmans (Tatars, Bachkirs, Russes, Allemands), comme on peut le voir dans le télégramme du Président de la Goubtchéka d'Oufa daté du 2 avril 1920 :

Le soulèvement dans la province d'Oufa est liquidé à l'aide de la force armée, de la propagande [agitacija] et de mesures importantes, la majorité des chefs est arrêtée. Le point de départ a été une politique alimentaire erronée, le comportant indigne des prodotrjady [...] et sur une base religieuse chez les musulmans (Данилов и Шанин 2002, 252).

\section{Le déroulement}

Dans la multitude de cas divers, on peut dégager une sorte de scénario classique qu'on retrouve tout au long de l'histoire de la Guerre civile ${ }^{12}$. Un détachement, fait de prodotrjady, de " paysans pauvres », de soldats, de miliciens, de communistes dans des proportions diverses, procède à une réquisition (le plus souvent de grains) de la manière violente de rigueur. Pour défendre ce qui constitue souvent leur dernière réserve, les paysans du village résistent, passent à tabac (dans certains cas tuent) les auteurs des réquisitions. Le tocsin sonne, tout le village s'assemble. Les paysans s'en prennent aux responsables locaux (soviet, communistes s'il y en a), cela peut aller de leur incarcération au meurtre.

Prévenues d'une manière ou d'une autre, des forces de l'ordre, dont la nature peut varier, arrivent dans le village et entament des négociations. À ce stade, on observe une alternative entre deux scénarios. Selon le premier, les parties trouvent un accord pour que le soulèvement se termine. Une répression suit, les « chefs », réels ou présumés, sont arrêtés, éventuellement fusillés, assez souvent sur place. Selon le second scénario, les paysans résistent au détachement venu briser la révolte. Parfois, d'ailleurs, le détachement en question passe du côté des révoltés avec ses armes. L'assemblée du village envoie des délégués dans les villages voisins, les appelant à se joindre à eux. Le canton entier se soulève, cherche à s'organiser, on élit de nouveaux soviets. Les nouveaux insurgés peuvent se joindre à des mouvements importants qui

12 Voir, par exemple, le récit post factum du soulèvement dans le gros village de Novodevitchie de la province de Simbirsk qui fut le point de départ de la " guerre des tchapans » (sorte de kaftan, vêtement chaud que portaient les paysans de la région de la Volta), fait par N. Petrov, l'agitator (littéralement agitateur, communiste s'occupant de la propagande) dans son rapport du 25 mars 1919. Voir également le rapport sur le déroulement du soulèvement dans toute la province de Simbirsk par le comité exécutif de Simbirsk adressé au NKVD en avril 1919 (Данилов и Шанин $2002,182-187 ; 237-243)$.

CONNEXE 7| 2021 - La Guerre civile après 1917 : les échelles d'un conflit et sa représentation 
existent déjà ou bien agissent seuls en s'organisant aussi militairement, ce que la présence de soldats, sous-officiers et parfois officiers de la Première Guerre mondiale rend plus aisé ${ }^{13}$.

On peut prendre comme exemple le soulèvement dans le district d'Ichim (Tioumen) en février 1921. Comme souvent, ce sont les réquisitions (celles des semences sont maintenues même après l'instauration de la NEP) qui constituent l'élément déclencheur. Des paysans se rendent en délégation auprès du commissaire à l'approvisionnement de leur district : « Donnez du blé, et puis vous pouvez emporter [le reste] ». Deux paysans sont tués. « Le soulèvement est spontané », dit l'auteur de la note de synthèse. Les communistes ne sont pas arrêtés au début, puis sont incarcérés sans violence. Sont envoyés 100 sabres (cavaliers) et 300 baïonnettes (fantassins). Ils tuent 300 insurgés, en blessent un nombre indéterminé et en arrêtent près de 1000. Le soulèvement à Ichim est liquidé. Mais le soulèvement gagne d'autres cantons et il s'ensuit l'embrasement général de la région et l'un des plus grands soulèvements paysans de toute la Guerre civile ${ }^{14}$.

Ce que craignent le plus les dirigeants du pays, ce sont les soulèvements d'unités militaires au complet, venant se joindre à un soulèvement déjà en cours ou même en constituer le point de départ, comme ce fut le cas, par exemple, de la neuvième division de cavalerie sous le commandement de Sapožkov et la création de son Armée de la Justice.

Malgré la tendance, dans les rapports, de qualifier tous les insurgés de " bandits », on trouve des textes parlant de soulèvements paysans et d'insurgés. Dans un rapport envoyé par l'État-major de la RKKA (Armée rouge) au Revvoensovet de la République, l'auteur (ou les auteurs) tente(nt) une typologie des insurgés. Le rapport commence par évoquer « la lutte contre les bandes de bandits et d'insurgés qui concernent d'énormes territoires de la partie centrale de la république ». Puis, après avoir énuméré les territoires concernés (Ukraine, régions limitrophes de l'Ukraine, Tambov et Voronej, la partie centrale de la Sibérie occidentale voisine de l'Oural et le centre du bassin de la Volga) et en avoir évoqué rapidement les causes (des raisons économiques exacerbées par les ennemis politiques du pouvoir soviétique), le texte passe à l'analyse des « bandes » :

Par leur composition et leur nature, les bandits peuvent être divisés en bandits d'origine locale, s'appuyant sur le soutien de la population de leur région dans laquelle ils opèrent, et en bandits, qui ne bénéficient pas toujours de la sympathie des gens venus d'ailleurs, souvent d'anciens chefs militaires insurgés contre le pouvoir

13 Ainsi A. Dolinin, lieutenant pendant la Première Guerre mondiale, fut un des commandants des insurgés dans la " guerre des kaftans » (Данилов и Шанин 2002, 823).

14 Note du 5 avril 1921 de P. Studitov, Président de la gubčeka de Tioumen (Шишкин 2001, 693-715). 
soviétique. Et enfin, des bandes de bandits de grand chemin (razbojniki) mus par l'appât du gain. Les plus dangereux sont les bandits d'origine locale bénéficiant de la sympathie de la population et poursuivant des buts économico-politiques ... (Данилов и Шанин 1994, 138).

La distinction entre les bandits [bandity] d'une part, associés aux insurgés [povstancy] et les razbojniki [brigands de grand chemin] d'autre part, indique que les premiers sont bien des insurgés et non des bandits. Le Bureau politique, lui, parle du soulèvement paysan (lors de sa réunion du 2 février 1921 consacrée à Antonov). Ainsi, il déclare à son point $\mathrm{b}:$ : [...] pour aider les camarades dans leur lutte contre le soulèvement paysan et pour procéder à un travail politique dans les territoires libérés des insurgés » (Данилов и Шанин 1994, 109).

\section{Mode d'action}

Alors que l'Armée rouge cherche des affrontements face à face afin que sa meilleure organisation, sa supériorité numérique dans la majeure partie des cas et son meilleur armement lui assurent la victoire, les insurgés préfèrent une guerre de partisans avec des raids rapides, coupures des voies ferrées, du télégraphe et téléphone, puis le retrait sur leur base arrière, cachés par les paysans, ou même en rentrant tout simplement chez eux. Comme l'affirma à l'époque le chef de l'État-major de la VOXR (Troupes de la défense intérieure de la République) « [...] le soulèvement se déplace facilement d'un groupe de villages à un autre, échappant aisément à nos forces et renforçant le nombre des insurgés » (Данилов и Шанин 1994, 61) ${ }^{15}$. Le service de renseignement auprès de l'État-major de la VOXR dénonce de manière encore plus explicite, le 15 avril 1921, la « couardise » d'Antonov et ses troupes : « le raid [d'Antonov contre un détachement de l'Armée rouge dans la région de Tambov] a démontré la couardise des bandits, qui fuient le moindre affrontement organisé » (Берелович и Данилов 1998, 412). Les chefs militaires cherchent de surcroit à se rendre mobiles aussi et demandent des troupes motorisées, des avions de reconnaissance, etc.

Lestrèsgrands mouvements allant, à en croireles rapports, jusqu'à 100000 insurgés, comme pour le "soulèvement des fourches », ou pour celui de Sibérie occidentale ${ }^{16}$, pouvaient être plus ou moins bien coordonnés. Ils n'étaient jamais réunis en une seule masse et se divisaient en des groupes ayant leur propre chef sous le commandement, plus ou moins bien admis, d'un État-major central. Les insurgés pouvaient d'ailleurs chercher à surmonter ce trop grand (selon eux) éparpillement et à regrouper les petits groupes en des forces plus organisées (Данилов и Шанин 1994, 142).

15 Rapport de V.V. Permjakov, chef d'État-major de la VOXR à l'adjoint du Revvoensovet de la République E.M. Skljanskij du 6 septembre 1920.

16 Selon V. Šiškin, rédacteur de la Sibirskaja Vandeja [Vendée de Sibérie], les insurgés, lors de la révolte de la Sibérie occidentale (février-avril 1921) arrivaient à un total de plus de cent mille personnes (Шишкин 2000, 6-7). 
Ces groupes (à l'exception des insurgés implantés dans le lieu de départ) étaient extrêmement mobiles : ils s'alliaient, se divisaient, se dissolvaient pour se recréer ailleurs. Si l'on prend au hasard une «bande » sous le commandement de Vas'ka Karas' (Carassin, son surnom, de son vrai nom Vasilij Nikitin-Korolëv) prenant part à l'antonovščina et ne présentant rien de particulier, on découvre, en suivant les rapports et les ordres de l'armée d'Antonov, qu'elle est née dans le district de Kozlov fin mars ou début avril 1921. En outre, une réunion des chefs des "petits détachements des armées de partisans de la région de Tambov » (le 2 avril) voulait regrouper les détachements en une brigade divisée en deux régiments, le tout sous le commandement de Karas'. Cependant, un rapport souligne que les 3000 hommes réunis étaient divisés en trois "régiments » (8 avril 1921), puis 1000 d'entre eux s'étaient mis sous le commandement direct d'Antonov et 1000 autres sous celui de Vasilij Seljanskij, les derniers 1000 restant avec Karas'. Le 21 avril, Karas' s'unit avec la « bande » de Marusja Nikiforova (venant d'Ukraine), constitue une force de 1200 sabres et rejoint Antonov le 22 avril. Le 28 avril, le détachement d'Antonov est signalé dans les environs de Voronej ; le 10 mai, selon un rapport de la Tchéka de Iaroslavl, les bandes réunies de Karas' et Voronik (non identifié) se sont dissoutes et les combattants sont rentrés chez eux. Puis, le 12 juillet, le détachement supposé dissout est soi-disant anéanti dans les environs de Vorontsovo (province de Tambov). En réalité, on le retrouve dans le rapport du 20 juillet 1921 de Vladimir Antonov-Ovseenko (président de la Commission plénipotentiaire du VCIK pour la répression de l'antonovščina) au Comité central du RKP, en train de saboter les voies ferrées entre Tambov et Kirsanov. Le 29 juillet, il diffuse des appels antisoviétiques contrel'impôt. Enfin, le 13 septembre, il combat encore en Volhynie, puis on perd sa trace (Берелович и Данилов 1998, 407 sq. ; Данилов и Шанин 1994, 142 sq.). Il est clair que ce genre de détachement a perdu le lien avec ses soutiens naturels (les paysans du district de Kozlov) et est obligé de réquisitionner chevaux et nourriture chez les paysans de la région où il se trouve, ce qui, à son tour, provoque une lassitude des paysans, dont profite le pouvoir soviétique $^{17}$.

Le problème posé au pouvoir soviétique n’était donc pas de battre tel ou tel détachement d'insurgés. Malgré des défaites ponctuelles, cela ne présentait pas, surtout après les défaites des forces «blanches », de difficultés particulières. La

17 Voir le rapport, déjà cité, du département secret de la VČK du 11 décembre 1921 : « Les fréquentes réquisitions de chevaux, de nourriture auxquelles procède Antonov ont considérablement réduitl'ardeur dela population environnante qui jusqu'à maintenant apportait de l'aide aux bandits "; il est vrai qu'un peu plus loin, le même rapport, toujours à propos d'Antonov, écrit que « la population est pleine de sympathie pour le mouvement, elle aide les bandits de toutes ses forces et par tous les moyens. Il arrive que quand nos troupes occupent un village, elles le trouvent parfaitement désert. Littéralement toute la population masculine, à part les enfants et les vieillards, a quitté le village » (Берелович и Данилов 1998, 367-368). Il est probable que les deux descriptions étaient exactes mais dépendaient de l'endroit où elles avaient été faites.

CONNEXE 7 | 2021 - La Guerre civile après 1917 : les échelles d'un conflit et sa représentation 
question était de savoir comment mettre fin à des soulèvements endémiques. Outre la réponse purement politique (l'instauration de la NEP), la solution militaro-politique était de contrôler le territoire et de terroriser les paysans qui aidaient les insurgés issus de leurs rangs. Mihail Tuhačevskij, chargé, sur décision du Politburo du 27 avril 1921, de mettre fin au soulèvement de Tambov en un mois (Данилов и Шанин 1994, 147-148), résumait la situation de la manière suivante dans sa note (classée secrète) adressée à Lénine le 16 juin 1921 :

L'anéantissement des forces vives des bandits ne présente pas de difficultés particulières grâce à leur faible capacité combattante. L'objectif le plus important et le plus difficile à atteindre est la conquête du territoire, l'occupation [souligné par l'auteur] et la soviétisation des sources de recrutement des bandes [c'est-à-dire rétablir le pouvoir soviétique dans les villages] (Данилов и Шанин 1994, 222).

\section{Réprimer et terroriser}

Il n'est pas question ici d'aborder la question de la violence durant la guerre Guerre civile qui, comme on le sait, fut sans limites des deux côtés. Les assassinats commis par les insurgés à l'encontre des communistes et responsables des soviets et parfois de leurs familles, tout comme les tortures suivies de mort infligées aux soldats de l'Armée rouge faits prisonniers, ont été abondamment exposées par l'historiographie soviétique. Bien entendu, ces violences sont aussi évoquées dans les rapports tant de la VČK que de l'Armée rouge ${ }^{18}$. Il convient néanmoins de distinguer la violence des insurgés de la terreur d'État exercée sur les paysans. Par ailleurs, la violence des insurgés a souvent été une réponse directe ou indirecte aux violences qui ont été exercées sur eux. Autrement dit, les soulèvements paysans ont eu lieu en réaction aux violences diverses subies (à commencer par les réquisitions). Comme cela a été mentionné précédemment, les insurrections importantes n'étaient pas organisées à l'avance mais ont souvent constitué une réaction à des représailles contre un soulèvement, parfois bref et relativement pacifique, d'un seul village.

Comme l'écrivent V. Danilov et V. Kondrašin, auteurs de l'introduction au recueil Le Mouvement paysans dans la région de la Volga « le sang coulait des deux côtés et la violence engendrait la violence. En fin de compte restait victorieux l'État qui disposait d'une supériorité technique et d'une meilleure organisation militaire. S'appuyant sur eux, il écrasait sans pitié les mouvements paysans ». Les auteurs donnent comme illustration le cas (il est vrai exceptionnel mais emblématique), qui s'est produit dans le village de Bakoury : en représailles à l'assassinat de trois envoyés du pouvoir, soixante

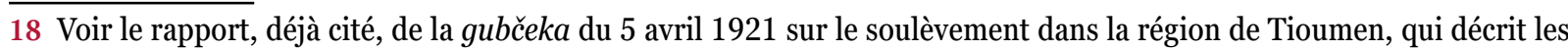
actes sauvages [zverstva] des insurgés. " Pour économiser les munitions, les prisonniers (communistes, soldats de l'Armée rouge) sont torturés à mort, [les insurgés procèdent à des] fusillades de masse, [on trouve] tous les membres d'une commune [agricole] égorgés, oreilles et nez coupés, brûlés au fer rouge, etc. » (Шишкин 2001, 709-710).

CONNEXE 7 | 2021 - La Guerre civile après 1917 : les échelles d'un conflit et sa représentation 
habitants furent fusillés sur place à la mitrailleuse sans enquête ni jugement (Данилов и Шанин 2002, 15, 83). Pour prendre un cas plus banal, après un soulèvement d'une semaine dans le canton de Jigoulev, où les communistes furent arrêtés mais étaient restés indemnes (le soulèvement s'était rapidement terminé car les paysans avaient libéré les détenus et levé les postes de garde), les troupes de représailles [karatelnye otrjady] ont " jugé » et fusillé sur place quatre insurgés et emmené dix-huit autres (Rapport du 18 mars 1918) (Данилов и Шанин 2002, 156-157).

Pour empêcher les paysans d'aider les insurgés et les obliger à les dénoncer, les bolcheviks pratiquèrent de manière systématique la prise d'otages et la responsabilité solidaire de tout le village. Ainsi, pour « liquider » le soulèvement de Sapožkov, Lénine ordonna le 2 août 1920 :

[...] 5) couper à la racine toute manifestation de sympathie pour Sapožkov et encore plus d'aide de la part de la population locale en utilisant tout le pouvoir révolutionnaire; là où des cas d'aide ont eu lieu, exiger qu'on livre les meneurs coupables ; prendre des otages dans les villages que doit traverser Sapožkov pour prévenir l'éventualité d’une aide [de leur part] (Данилов и Шанин 2002, 533 ; Ленин 1970, 347-348).

La montée du terrorisme d'État exercé contre les régions insurrectionnelles ressort très clairement de la lutte menée dans la région de Tambov contre Antonov après la nomination de Mihail Tuhačevskij (militaire) et Vladimir Antonov-Ovseenko (civil) à la tête de la répression suite à l'ordre ${ }^{\circ} 130$ du 12 mai 1921 de Tuhačevskij et la décision de la commission du VCIK à la même date (Данилов и Шанин 1994, 162).

L'escalade de la répression culmine avec le tristement célèbre ordre $\mathrm{n}^{\circ} 171$ de la Commission plénipotentiaire du VCIK en date du 11 juin 1921, signé par les deux chefs et deux autres protagonistes. Cet ordre est basé sur une réunion précédente de la Commission datant du 9 juin (qui préconisait, en outre, en son point 4, le recours aux gaz pour « enfumer » les bandits) (Данилов и Шанин 1994, 176-178; 178-179). L'ordre $\mathrm{n}^{\circ} 171$ mérite d'être cité largement :

Fusillez les personnes qui refusent de donner leur nom ;

Dans un village où sont dissimulées des armes, prendre des otages et les fusiller si les armes ne sont pas livrées ;

Fusiller sur place le chef de famille [vivant] dans la maison où ont été trouvées des armes :

Le chef de la famille où se cachait un bandit est fusillé sur place, la famille est arrêtée et déporté ;

Les membres des familles cachant les familles de bandit ou des biens appartenant à des bandits, doivent être considérés comme des bandits et le chef de famille sera fusillé sur place (Данилов и Шанин 1994, 179) (voir Document 3). 
Ce chef d'œuvre de sauvagerie sera précisé par d'autres ordres spécifiant la procédure de la prise d'otages lors du « nettoyage » des cantons les plus « contaminés » par le banditisme : on encercle le canton par des troupes, on prend les « 60-80 otages les plus en vue ». On avertit la population qu'elle a deux heures pour livrer armes, bandits et familles de bandits. Si la population ne collabore pas, les otages sont fusillés et on prend de nouveaux otages en donnant de nouveau deux heures de délai. « En cas d'entêtement, on fusille de nouveau, etc. [sic]». Dernier raffinement : les villageois qui ont dénoncé les bandits sont constitués en groupes chargés d'aider à la capture des bandits (Данилов и Шанин 1994, 188).

L'ordre sera suspendu sur une décision de la Commission de la lutte contre le banditisme auprès du Revvoensovet de la République le 19 juillet. Tuhačevskij et Antonov-Ovseenko sont déplacés après une réunion du Politburo, lors de laquelle plusieurs membres furent horrifiés par les mesures prises (Данилов и Шанин 1994, 227).

\section{Conclusion}

Comment la répression va-t-elle prendre fin ? On peut relever plusieurs causes. Certes, comme nous l'avons vu, la terrorisation de la population paysanne ainsi que la famine qui a touché des régions où les insurrections étaient importantes (les régions de la Volga, en particulier) ont joué un rôle clé. Un autre élément est la lassitude des paysans, qui souhaitent retrouver leur activité habituelle, cultiver leur terre et nourrir leur famille. L'instauration de la NEP rendit possible le travail agricole en satisfaisant partiellement les revendications des paysans ${ }^{19}$. Ce compromis entre les paysans et le pouvoir bolchévique dura jusqu'au retour des réquisitions en 1928 et le Grand tournant, que la paysannerie associa aussitôt à un retour aux pratiques $\mathrm{du}$ « communisme de guerre ». Le pouvoir reprit alors le savoir-faire acquis durant la guerre contre les paysans avec la conviction que l'usage de la force était le gage assuré du succès final. Les paysans, en revanche, n'avaient plus alors les instruments dont ils avaient disposé en 1918-1922. Ils n'avaient ni armes, ni chefs militaires, ni possibilité de contacts. La guerre contre les paysans, comme la Guerre civile en général, furent bel et bien la matrice du régime soviétique.

19 On peut s'interroger sur les raisons qui ont poussé Lénine et les dirigeants bolchéviques à adopter la NEP. On avance parfois l'idée que c’était la peur d'un soulèvement général de la paysannerie. Il me semble que l'examen des rapports nous permet d'avancer l'hypothèse que les bolcheviks ne craignaient pas, après la victoire sur les "Blancs ", une défaite militaire face aux paysans. On peut supposer qu'ils prirent conscience du fait qu'il fallait que les paysans fournissent, sèment et moissonnent le blé pour que le pays survive. Ils comprirent donc qu’il était nécessaire de trouver un compromis. 


\section{Références bibliographiques}

Badcock, Sarah, Novikova, Liudmila, and Retish, Aaron, eds. 2015. Russia’s Home Front In War And Revolution, 1914-22, Book 1, Russia's Revolution In Regional Perspective. Bloomington, IN: Slavica Publishers.

Brovkin, Vladimir N. 2015. Behind the front lines of the civil war: political parties and social movements in Russia, 1918-1922. Princeton, NJ: Princeton University Press.

Chopard, Thomas. 2015. Le Martyre de Kiev : 1919. L'Ukraine en révolution entre terreur soviétique, nationalisme et antisémitisme. Paris : Vendémiaire.

Chopard, Thomas. 2019. «L'ère des atamans. Politique, guerre civile et insurrections paysannes en Ukraine (1917-1923)». Revue d'histoire 141 : 55-68.

Graziosi, Andrea. 1996. The Great Soviet Peasant War. Bolsheviks and Peasants, 1917-1933. Cambridge, MA: Ukrainian Research Institute Harvard University.

Holquist, Peter. 2002. Making War, Forging Revolution: Russia’s Continuum of Crisis, 19141921. Cambridge, MA: Harvard University Press.

Landis, Erik, C. 2008. Bandits and Partisans: The Antonov Movement in the Russian Civil War. Pittsburgh, PA: University of Pittsburgh Press.

Landis, Erik-C. 2004. «Between village and Kremlin : Confronting state food procurement in civil war Tambov, 1919-1920. » Russian Review 63 (1) : 70-88.

Raleigh, Donald J. 2002. Experiencing Russia's Civil War: Politics, Society, and Revolutionary Culture in Saratov, 1917-1922. Princeton, NJ: Princeton University Press.

Retish, Aaron. 2008. Russia's Peasants in Revolution and Civil War: Citizenship, Identity, and the Creation of the Soviet State, 1914-1922. Cambridge, MA: Cambridge University Press.

Retish, Aaron. 2015. « The Izhevsk Revolt of 1918: The Fateful Clash of Revolutionary Coalitions, Paramilitarism, and Bolshevik Power.» In Russia's Home Front In War And Revolution, 1914-22, Book 1, Russia's Revolution In Regional Perspective, eds. Sarah Badcock, Liudmila Novikova, and Aaron Retish, 229-322. Bloomington, IN: Slavica Publishers.

Werth, Nicolas. 2002. « Les rebelles primitifs en URSS. De la guerre civile à la sortie de la Seconde guerre mondiale ». Communisme 70-71:60-91.

Werth, Nicolas. 2011. « Les campagnes soviétiques pendant les guerres civiles et la NEP. 19181929 ». Dans L'État soviétique contre les paysans. Rapports secrets de la police politique, éd. Nicolas Werth, et Alexis Berelowitch, 35-239. Paris : Tallandier.

Берелович А., и В. Данилов, ред. 1998. Советская деревня глазами ВЧК-ОГПУ, Том 1, Документы и материалы. Москва : Росспэн.

Буденный С., и др., ред. 1960. История гражданской войны в СССР, Том 5. Москва : Институт марксизма-ленинизма при ЦК КПСС.

Данилов В., и Т. Шанин, ред. 1994. Крестьянское восстание в тамбовской губернии в 1919 -1921 ге. "Антоновщина », Документы и материалы. Тамбов : Редакционноиздательский отдел.

Данилов В., и Т. Шанин, ред. 1997. Филипп Миронов, Тихий Дон в 1917-1921 ге. Москва : Международный фонд « Демократия ». 
Данилов В., и Т. Шанин, ред. 2002. Крестьянское движение в Поволжье, 1919-1922, Документы и материалы. Москва : Росспэн.

Данилов В., и Т. Шанин, ред. 2006. Крестьянское движение на Украине, 1918-1921. Документы и материалы. Москва : Росспэн.

Кондрашин В. 2009. Крестьянство России в Гражданской войне : к вопросу об истоках сталинизма. Москва : Росспэн.

Кондрашин В. 2013. « Отечественная и зарубежная историография крестьянского повстанческого движения в России в годы гражданской войны ». Крестьянский фронт, ред. А. В. Посадский, 24-47. Москва : АИРО-ХХІ.

Кондрашн В. 2018. " О достижениях и проблемах современной отечественной историографии крестьянского повстанческого движения в России в годы Гражданской войны ". Вестник самарского университета, История, педагогика, филология 24 (1) : 39-45.

Ленин В. 1970. Полное собрание сочинений, пятое издание, том 51. Москва : Издательство политической литературы.

Осипова Т. 1995. «Крестьянской фронт в гражданской войне ». Судъбы российского крестьянства, ред. Ю. Афанасьев, 90-162. Москва : РГГУ.

Осипова Т. 2001. Российское крестьянство в революции и гражданской войне. Москва : Стрелец.

Теплицын В. 2002. « Бунтующий землепашец : 1917-1920 гг. ». Гражданская война 8 России. События, мнения, оценки, ред. Н. Ивницкий, 579-596. Москва : Раритет.

Шанин Т. 2006. « Крестьянские войны в России. 1902-1922 ». Крестьяноведение, Теория. История. Современность, ред. Т. Шанин и А. Никулин. Ученые записки 2005. Выпуск $5: 30-37$. Москва : Московская высшая школа социальных и экономических наук.

Шишкин В., ред. 2000. Сибирская Вандея, Том 1, 1919-1920. Москва : Международный фонд « Демократия ».

Шишкин В., ред. 2001. Сибирская Вандея, Том 2, 1920-1921. Москва : Международный фонд « Демократия ».

Open Access Publications - Bibliothèque de l'Université de Genève

Creative Commons Licence 4.0

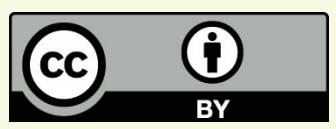

CONNEXE 7 | 2021 - La Guerre civile après 1917 : les échelles d'un conflit et sa représentation 


\section{Annexes}

On trouvera ci-après in-extenso des documents dont des extraits ont été cités ou évoqués dans le corps de l'article.

\section{- $\quad$ Document 1.}

Le premier document comportant deux extraits (Данилов и Шанин 2002) nous fait entendre, à travers les appels lancés à la population, les voix des paysans insurgés d'un des plus grands mouvements de révolte, la « guerre des kaftans » [Čapannaja vojna] (du nom du vêtement d'hiver porté par les paysans de la région de la Volga) qui a mobilisé en mars 1919 plus de 100000 hommes.

- Document 2.

Ce document, publié en 1998 (Берелович и Данилов 1998), nous montre dans le détail la multitude et la diversité des soulèvements paysans en novembre 1919 à travers toute la Russie et la mobilisation de la Vétchéka pour les écraser.

- Document 3.

Les deux derniers extraits (Данилов и Шанин 1994) nous permettent de voir les moyens mis en œuvre pour en finir avec le soulèvement emblématique de la région de Tambov (l'Antonovščina) et le regard porté sur le soulèvement par le chef militaire Mihail Tuhačevskij dans son rapport à Lénine. 


\section{Document 1}

Крестьянское движение в Поволжье, 1919-1922, документы и материалы, под редакцией В. Данилова и Т. Шанина, Москва, РОССПЭН, 2002 [Le Mouvement paysan dans la région de la Volga, 1919-1922, documents et matériaux, V. Danilov et T. Shanin éd., Moscou, ROSSPEN, 2002], pp. 103-104.

\section{«Чапанная война »}

\section{Возвания повстанцев}

8-12 марта 1919 г.*

[Обращение штаба повстанцев к крестьянам]

Товарищи и братья крестьяне всей России !

Мы восставшие крестьяне - труженики, мы - сыны земли и главный фундамент государства, обращаемся к Вам и заявляем, что мы восстали против засилия и произвола тиранов, палачей коммунистов-анархистов, грабителей, которые прикрывались идеей коммунизма, присасывались к Советской власти. Мы объявляем, что Советская власть остается на местах, советы не уничтожаются, но в советах должны быть выборные лица известные народу - честные, но не те присосавшиеся тираны, которые избивали население плетями, отбирали последнее, выбрасывали иконы и т.п.

Товарищи и братья крестьяне ! Мы призываем Вас и просим примкнуть к нам и сплотиться воедино в борьбе за справедливое дело. Да здравствует Советская власть на платформе Октябрьской революции !

\section{Начальник итаба Крох}

ГАРФ, Ф.1235, Оп. 94, Д. 64, Л. 83. Копия

* Воззвания не имеют дат. Датировка дается по событиям, а также по другим документам в архивном деле.

[Обращение штаба повстанцев к гражданам]

Граждане ! Обращаемся к вам и объявляем волю населения сел и деревень, восставших против диктатуры коммунистов. Население сел и деревень - все единодушно заявили, что власть должна оставаться Советская.

Население в корне протестует против засилия коммунистов.

Население сел и деревень в корнепротестует против убийств обезоруженных коммунистов и вообще против бесцельного кровопролития.

СОГАСПИ, Ф. 3500 , ОП. 1, Д. 293, Л. 57а, копия 
Возвание от Трудовой крестьянской рабочей рукомозолистой партизанской армии*

Граждане!

Час настал... Соединимся все воедино на защиту своих народных прав и достояния трудового народа, разграбляемого шайкой хулиганов, лодырей, лентяев и любителей чужого, кровавым потом нажитого имущества - насильников-коммунистов.

Граждане!

Эти выходцы Карла Маркса и Энгельса, это [их] потомство представляет собою крыловскую "Свинью под дубом вековым »**, они так же, как достопримечательная свинья, которая не сеяла и не садила эти вековечные дубы, нажравшись желудей до отвала, у дуба корни подрывать стала. Вековечный дуб, граждане, это трудовое крестьянство, которое веками несло тяжести и лишения, как в монархизме, так и во все те тяжелые годины крепостничества ; крестьянство спало как медведь в берлоге, которого не трогала рогатина, по которому ползали различные насекомые, букашки, всевозможные гады и он терпеливо переносил все их кусы и ужаления, но как только медведь почувствовал холодную сталь просунутой в берлогу рогатины, он выскочил из берлоги и начал метать направо и налево подступивших к нему охотников и собак. Итак, крестьяне, настала пора и нам, как крыловскому*** медведю, проснуться и разметать всех действительных гадов человечества - коммунистов, которые высасывают кровь трудового крестьянства и последние соки из его кровавым потом нажитого имущества.

* Собственный заголовок документа.

** Имеется в виду басня « Свинья под дубом » (1825) И. А. Крылова (1769-1844) [note AB].

*** Ошибка авторов возвания, такой басни у Крылова нет [note AB].

Граждане!

Вооружимся все до единого, от старого до малого на защиту своих кровных прав и сотрем с лица земли присосавшуюся к нам коммуну. Будем все бороться до последней капли крови и горе всем тем, которые отступят хоть на йоту от защиты трудовых крестьянских прав.

Да здравствуют советы крестьянских народных депутатов !

Да здравствует трудовая рукомозолистая Крестьянская армия !

Да здравствует крестьянство, восставше на защиту своих прав и свободного труда !

Авторы Я. А. и И. С. Королевы

Переписать и послать в следующее селение, написав, чтобы и это селение по снятии копии переслало в следующее селение и т.д.

ГАРФ. Ф. 1235, Оп. 94, Д. 64, Л. 84-84 об. Рукописный подлинник

CONNEXE 7| 2021 - La Guerre civile après 1917 : les échelles d'un conflit et sa représentation 


\section{Document 2}

Советская деревня глазами ВЧК-ОГПУ-НКВД. Документы и материалы, том 1 , 1918-1922, под редакцией А. Береловича, и В. Данилова, Москва, РОССПЭН, 1998. [Les Campagnes soviétiques vues par la VČK- OGPU-NKVD. Documents et matériaux, tome 1, 1918-1922, A. Berelowitch et V. Danilov éd., Moscou, ROSSPEN, 1998], p. 104.

\section{Из сводки оперативного отдела штаба корпуса войск ВЧК об участии частей корпуса в подавлении контрреволюционных восстаний за период с 1 октября по 25 ноября 1918 г.*}

Не ранее 25 ноября 1918 г.**

* Заголовок документа.

** Дата установлена по содержанию.

\section{Орловский округ}

... Курский батальон. 15 ноября. Отрядом батальона при Фатежской чрезком подавлено восстание в Сдобниковской вол. Арестованы 53 человека и отобрано оружие. 25 ноября. Частями батальона подавлены беспорядки на почве отбора хлеба и в связи с мобилизацией духовенства в Болшежировской, Сергиевской и Сдобниковской вол.

\section{Уральский округ}

Вятский батальон. Сведений не поступало.

Пермский батальон. ... 27 сентября. Ликвидировано восстание в Усольском у., вспыхнувшее на почве реквизиции хлеба у кулаков. Восставшими был обезоружен отряд, который реквизировал хлеб. Кулаки забрали оружие отряда и восстали против Советской власти. Восставшие были обезоружены, отобран один пулемет и оружие. Зачинщики пойманы и расстреляны...

\section{Петроградский округ}

Петроградский баталъон. Сведений не поступало.

Псковский батальон. Батальон с половины октября находился на подавлении контрреволюционных восстаний. До начала ноября части батальона подавили восстания в Дунаевской и Невской вол...

\section{Ярославский округ}

Вологодский батальон. Сведений не поступало.

Северо-Двинский батальон. Сведений не поступало.

Ярославский баталъон. ... 30 октября. Частями Мышкинской и Рыбинской чрезком подавлено восстаниев волостях Мологскогоу., гдевосставшие отказались от мобилизации, разбили военком и Совет...

20 ноября. Частями Рыбинской роты подавлено кулацкое восстание в Пошехонском у.

Тверской батальон. ... 12 ноября. Частями батальона подавлено восстание белогвардейцев, поддержанное мобилизованными и кулаками. В Осташковском и 
Ржевском у. при ликвидации мятежа убиты около 200 белогвардейцев, расстреляны пять зачинщиков, арестованы свыше 50 человек, в восстании замешаны члены кредитных и кооперативных товариществ. Созданы новые правления.

21 ноября. Части батальона находятся на подавлении кулаков и белогвардейцев в Сычевском у. Смоленской губ. 25 ноября. Восстание подавлено.

В Субботинской вол. крестьянами дер. Двоенки и Подберезовки зверски убиты трое ; среди них член Зубцевского Исполкома Павлов (по имеющимся сведениям, зарыт живым, что видно из того, что в могиле оказалось много крови). Трупы вырыты в одном белье и отправлены в Зубцов. Отряд Тверского батальона возвращается обратно.

Иваново-Вознесенский батальон....23 ноября. Ликвидирована попытка квооружению кулаков дер. Петрово Городнищенской вол. Ржевского у. Кулаки арестованы.

Владимирский батальон. ... 9 ноября. Отряд из Владимирского батальона под командой т. Исаева участвовал в ликвидации восстания в Касимовском у. Рязанской губ. Расстреляли 12 главарей. Восставшие волости обложены контрибуцией, которая внесена в местные учреждения без сопротивления и задержки. Мобилизованные солдаты, отказывавшиеся раньше идти, явились на учет и регистрацию.

\section{Московский округ}

Витебский батальон. ... С 13 ноября. Части батальона участвовали на подавлении белогвардейских и кулацких мятежей и восстаний по губернии. Больше сведений не поступало.

Смоленский батальон. 16 октября. Отправлено подкрепление из частей батальона в Вятские Поляны в распоряжение Реввоенсовета 2-й армии для подавления восстаний в районе Ижевского-Боткинского завода... 9 ноября. Духовщинским отрядом Смоленского батальона подавлено кулацкое восстание, организованное левым эсером Ивановым. Восставшими был захвачен город, телеграф и станция. Духовщинский отряд до прибытия подкрепления выбил противника и занял город и телеграф. Руководитель восстания был убит, остальные в панике бежали. 16 ноября. Части батальона участвовали в подавлении восстаний в Сычевке, Белом, Духовщине, Велиже, Лезно, Поречье ; восстания подавлены, люди батальона разосланы по волостям для окончательного уничтожения кулаков.

Московский батальон. 16 октября. Отправлено подкрепление из частей батальона в Вятские Поляны в распоряжение Реввоенсовета 2-й армии, для подавления восстания в районе Ижевско-Воткинского завода. 12 ноября. Части батальона участвовали в подавлении восстания в Можайском у., где четыре волости восстали против Совета. 17 ноября. Отряд из батальона участвовал в подавлении восстания в Гжатске и уезде. Восстание ликвидировано, отряд возвратился. 19 ноября. Отряд из батальона послан на подавление восстания в Волоколамском у. у разъезда Муриково и Елатонь.

Калужский батальон... 14 ноября. Части батальона участвовали в подавлении восстания в Медынском и Боровском у. Восстания подавлены, батальон потерял в боях одним убитым и тремя ранеными.

Рязанский батальон. 16 октября. Отправлено подкрепление из частей батальона в Вятские Поляны в распоряжение Реввоенсовета 2-й армии для подавления восстаний в районе Ижевского-Боткинского завода. $C 4$ ноября. Части батальона находились на подавлении ряда контрреволюционных выступлений в губернии. Участвовали в подавлении восстаний мобилизованных в Касимовском, Раннебурском, Сапожковском,

CONNEXE 7| 2021 - La Guerre civile après 1917 : les échelles d'un conflit et sa représentation 
Пронском, Михайловском и Рязанском у., а также на линии Рязань-Ряжск : ст-и Хрущеве, Шилове, Юзиково, Александ-ро-Невская, Урусове, Чемодановка, Биркино. Восстания подавлены. Части батальона принимали участие в подавлении восстаний в Тамбовской губ. в Шацком у.

Тамбовский батальон. 16 октября. Отправлено подкрепление из частей батальона в Вятские Поляны в распоряжение Реввоенсовета 2-й армии для подавления восстаний в районе Ижевско-Воткинского завода.

16 ноября части батальона принимали участие в подавлении восстаний на линии Рязань-Ряжск в 30 верстах от ст-и Кирсанове и в 5 верстах от ст-и Ломовис. На ст-и Лайки подавили восстание кулаков и части Красной Армии.

C 4 по 25 ноября. Части батальона находились на подавлении восстаний по Тамбовской губ. в Шацком и Моршанском у. Восстания были организованы в связи с мобилизацией, распространялись воззва ᄀния « Долой Советскую власть ! » Восстания подавлены, части батальона возвращаются. Из строя батальона выбыли в боях при ликвидации восстаний 24 человека.

\section{Приволжский округ}

Нижегородский батальон. 16 октября. Отправлено подкрепле Вятские Поляны в распоряжение Реввоенсовета 2-й армии для подавления восстания в районе Ижевско-Воткинского завода.

Отряд при Казанской чрезком. 20 ноября. Подавлено восстание кулаков в Адаровской и Черемышской вол. Лаишевского у. - расстреляны 10 человек, арестованы 30, с нашей стороны ранен один. Взято 10 возов оружия. Послан отряд в с. Шумково Лаишевского у. от Лаишевской чрезком для подавления восстания дезертиров и кулаков. Подавлено восстание в окрестностях г. Арска, расстреляны 40 человек, ранены 20, арестованы около 310 человек, отобрано разного оружия 500. Наложена контрибуция 400 тыс. руб. и 25 тыс. пуд. хлебом. Конфискованы две фабрики валеных и одна кожевенная, одна паровая мельница, 28 подвод кож в сыром виде, 280 шапок. Все сдано в распоряжение бедкомов***. С нашей стороны пали в бою четыре красноармейца и военный комиссар. Саратовский батальон. 16 октября. Отправлено подкрепление из батальона в Вятские Поляны в распоряжение Реввоенсовета 2-й армии для подавления восстания в район ИжевскоВоткинского завода. 16 ноября. Частями батальона подавлено восстание в Александровке Саратовского у. 13 ноября. Послан отряд во главе с комбатом Наклоновым на подавление контрреволюционного восстания в с. Базарный Карабулак Саратовской губ.

*** Имеются в виду комитеты бедноты.

Пензенский батальон. 20 ноября. Приняты меры к недопущению ожидающегося контрреволюционного восстания мобилизованных в Саранске.

Наштакор ВЧК К.Валобуев

Завоперод Саввин

РГВА. Ф.6. Оп.10. Д.9. Л.28. Подлинник. Ф. 16011. Оп.1. Д.2. Л.29-32. Подлинник. 


\section{Document 3}

Крестьянское восстание в тамбовской губернии в 1919-1921 г2. « Антоновщина ». Документы и материалы, под редакцией В. Данилова и Т. Шанина, Тамбов, 1994. [Le Soulèvement paysan dans la province de Tambov en 1919-1921. L' " Antonovščina ». V. Danilov et T. Shanin éd., Tambov, 1994], pp. 178-179 et 222.

\begin{tabular}{|l|} 
Приказ Полномочной комиссии ВЦИК о начале проведения репрессивных мер \\
против отдельных бандитов и укрывающих их семей \\
$N$ 171, г. Тамбов \\
11 июня 1921 г.
\end{tabular}

Уполиткомиссиям 1, 2, 3, 4, 5

Начиная с 1 июня решительная борьба с бандитизмом дает быстрое успокоение края. Советская власть последовательно восстанавливается, и трудовое крестьянство переходит к мирному и спокойному труду.

Банда Антонова решительными действиями наших войск разбита, рассеяна и вылавливается поодиночке.

Дабы окончательно искоренить эсеро-бандитские корни и в дополнение к ранее отданным распоряжениям Полномочная комиссия ВЦИК приказывает :

1. Граждан, отказывающихся называть свое имя, расстреливать на месте без суда.

2. Селениям, в которых скрывается оружие, властью уполиткомиссии или райполиткомиссии объявлять приговор об изъятии заложников и расстреливать таковых в случае несдачи оружия.

3. В случае нахождения спрятанного оружия расстреливать на месте без суда старшего работника в семье.

4. Семья, в доме которой укрылся бандит, подлежит аресту и высылке из губернии, имущество ее конфискуется, старший работник в этой семье расстреливается без суда.

5. Семьи, укрывающие членов семьи или имущество бандитов, рассматривать как бандитов, и старшего работника этой семьи расстреливать на месте без суда.

6. В случае бегства семьи бандита имущество таковой распределять между верными Советской власти крестьянами, а оставленные дома сжигать или разбирать.

7. Настоящий приказ проводить в жизнь сурово и беспощадно.

Председатель Полномочной комиссии ВЦИК

Антонов-Овсеенко

Командующий войсками Тухачевский

Председатель губисполкома Лавров

Секретарь Васильев

Прочесть на сельских сходах.

ГАТО.Ф.Р.-4049. Оп.1. Д.5. Л.45. Типографский экз.

CONNEXE 7 | 2021 - La Guerre civile après 1917 : les échelles d'un conflit et sa représentation 
Советизация должна была проводиться следующими мерами : изъятием бандитского элемента, насаждением ревкомов, расслоением крестьянства путем вооружения его против бандитизма, заинтересовывая его материально за счет конфискационных имуществ бандитов, применением террористических мер против сочувствующих бандитизму, извлечением комитетов СТК, трудовой помощью Красной Армии населению и налаживанием советской работы.

Параллельно с этим был намечен ряд маневренных операций против банд, каковые и должны были окончиться полной гибелью последних от истощения (источники комплектования оккупированы).

\section{III. Достигнутые результаты и дальнейшие мероприятия}

В результате методически проведенных операций на протяжении сорока дней крестьянское восстание в Тамбовской губ. ликвидировано.

СТК разгромлен.

Советская власть восстановлена повсеместно.

От 21000 бандитов осталось к 11 июля лишь 1200 сабель. Громадное количество главарей банд уничтожено.

Крестьянство скомпрометировано в глазах бандитов и ищет от них вооруженной защиты Красной Армии.

Но вместе с тем крестьяне определенно не верят в искренность декрета о продналоге. Среди них ходят слухи о том, что к осени наши войска будут выведены из Тамбовской губ. и тогда бандиты вновь начнут действия и, наконец, кое-где еще сидят волостные комитеты СТК.

В виду этого я считаю необходимым проведение нижеследующих мероприятий :

1. не выводить из Тамб[овской] губ[ернии] ныне действующих в ней войск в течение одного года;

2. оставить оккупационное командование в Тамб[овской] губ[ернии] по крайней мере до зимы, не увлекаясь сокращением штабов;

3. всех коммунистов, присланных по мобилизации в Тамб[овскую] губ[ернию], закрепить за последней, а также произвести перегруппировку засидевшихся коммунистов;

4. не налагать на Тамб[овскую] губ[ернию] никаких дополнительных продовольственных налогов.

Тухачевский ${ }^{*}$

РГВА. Ф.33988. Оп.2. Д.324. Л.36-40. Заверенная копия

\footnotetext{
** На копии документа имеется приписка о наличии в подлиннике собственноручной резолюции т. Ленина : «Секретно. Товарищу Троцкому. Троцкий. Черкните, что из этого предрешено ? 29/VII. Ленин. " в заверенной надписи к копии документа, снятой в 1924 г., указывается : «Подлинная записка (доклад) т. Тухачевского с собственноручной резолюцией т.Ленина из настоящего дела изъята и приобщена к переписке тт. Ленина и Троцкого. 5 августа 1924 г. Квасников ».
} 